\title{
Who are the actual beneficiaries of health promotion? An evaluation of health promotion scope in Yogyakarta
}

\author{
Baiquni Fahmi*, Kusumaningrum Fitrina, and Supriyati Supriyati
}

Department of Health Behavior, Environment and Social Medicine, Faculty of Medicine, Public Health and Nursing, Universitas Gadjah Mada, Jl. Farmako Sekip Utara, Yogyakarta 55281 Indonesia.

\begin{abstract}
Healthy lifestyle media campaign is one of health promotion method that offers a challenge in evaluation. Healthy lifestyle media campaign doesn't usually result in behaviour change because the changing needs times and provision of other interventions. This study was trying to evaluate a healthy lifestyle media campaign developed by District Health Office of Yogyakarta using the RE-AIM framework. The mixed method study consists of a quantitative approach to describe the reach of media campaigns and the qualitative approach to describe public perception of media campaign effectiveness. This study's total sample is 288 respondents ( $32+11$ y.0; $57.56 \%$ women) consists of community, cadres, and students. The data were collected through survey, in-depth interviews and focus group discussions. Healthy lifestyle media have not been able to reach all respondents. Nine from 11 produced media were not known by more than $60 \%$ respondents. Respondents describe media distribution, media placement, media competition and channel suitability as the factors that affect their familiarity with healthy lifestyle media campaign. Not all media could reach enough target in the community. Health promoter should take notice on the media's ability to reach specific targets when developing the media campaign.
\end{abstract}

\section{Introduction}

Health promotion is known as the means to improve the ability of the community to maintain and improve their health [1]. Time and participation from all elements of the community are needed to ensure the effectiveness of health promotion. Effective health promotion should also be carried out at the various levels of ecological level [2]. Recently, health promotion media has become an important strategy to disseminate health information. Improvement in information technology enables health promoters to produce effective media campaigns and understand community needs [3]. As the main process of health promotion, understanding community needs is also an important point the development of health promotion [4].

Various studies had also shown that media campaign played important part in the effectiveness of health promotion. In tobacco control, the provision of pictorial health warning was effective in informing the community about the danger of smoking [5, 6]. Research also showed that people who actively access health information through mass media would be more likely to involve the offered health promotion program [7]. In breastfeeding issues, most mothers would prefer to access information through internet [8].

Indonesia is a high populous country with very vast sociocultural characteristics. In 2018, healthy lifestyle was still one of the health problems in Indonesia that determined the high prevalence of non-communicable diseases [9]. Yogyakarta city is the capital of Indonesia's province with a unique characteristic of its community. Unlike other urban region, Yogyakarta city was known to have a close-knit community. In 2015, Yogyakarta city had the highest proportion of household $(49.41 \%)$ which applied healthy behaviour and cleanliness indicators (perilaku hidup bersih dan sehat/PHBS). The district health office of Yogyakarta city had partnered with other organizations to ensure the application of these indicators by promoting healthy behaviour and cleanliness in schools, primary health centers, and other public areas [10]. District health office was also encouraged the community to adopt independent waste management by sorting household's waste [11].

In campaigning healthy behaviour and cleanliness to community, District Health Office of Yogyakarta city also developed health promotion media, such as posters, leaflets, and billboards. However, there hadn't been any evaluation regarding the effectiveness of these media in reaching community as well as change community behaviour to adopt healthy lifestyle and practice cleanliness until now. Evaluation is an important process in health promotion for this process can inform the health promoter of the program's effectiveness and the improvement needed for the next program.

A health promoter can use many evaluation frameworks to evaluate program success using certain

* Corresponding author: fahmibaiquni@mail.ugm.ac.id 
indicators [12-14]. Reach, Effectiveness, Adoption, Implementation, Maintenance (RE-AIM) framework is one of the evaluation frameworks used by many programs to evaluate the program's effectiveness, especially for those that used socio-ecological approach. The application of this framework was known to encourage the improvement of the program and to the framework itself [15-17]. This study was intended to evaluate the media campaign on healthy lifestyle and cleanliness developed by District Health Office of Yogyakarta city. The evaluation will be conducted using RE-AIM framework to ensure the improvement of the program.

\section{Methods}

This research used a mixed-method approach. Quantitative method using cross-sectional approach was carried out to determine the Reach of the healthy lifestyle and cleanliness media produced by District Health Office of Yogyakarta city. Descriptive qualitative method is used to describe the Adoption and Effectiveness of the media campaign by asking respondents' perceptions of the media developed by District Health Office of Yogyakarta city.

\subsection{Participants}

Total number of participants in this study were 288 participants. The detailed characteristics of the participants were shown in Table 1. Participants of quantitative research were selected by purposive sampling. Respondents consisted of health cadres, high school students and elementary school students. The health cadres were selected using inclusion criteria: village cadres from Yogyakarta city and had experienced at least $1 \mathrm{yr}$. The participants from high school students were selected with inclusion criteria: age more than $17 \mathrm{yr}$ old and Yogyakarta city residents for the last 6 mon. The participants from elementary school students were selected with inclusion criteria: aged between $10 \mathrm{yr}$ to $11 \mathrm{yr}$, residents of Yogyakarta city and got permission from parents to participate in research.

Participants in qualitative research were selected purposively with inclusion criteria: residents living in Yogyakarta city for at least 6 mon and aged 13 yr old to 70 yr old. Participants were selected using maximum variation technique with variations in socioeconomic status (upper middle and lower middle) and the age of respondents (adolescents (13 yr to $24 \mathrm{yr}$ ), adults ( $25 \mathrm{yr}$ to $60 \mathrm{yr}$ ) and old age (61 yr to $70 \mathrm{yr}$ ). Selection of criteria based on previous research which showed that the selection and access to media was influenced by age and socioeconomic status $[19,20]$. The detail of qualitative participants variation is provided in Figure 1. To ensure the validity of the data, in-depth interviews were conducted with 1 health promotion media expert.
Table 1. Demographic characteristics of study participants

\begin{tabular}{|l|c|c|c|c|c|c|}
\hline \multirow{2}{*}{$\begin{array}{c}\text { Demography } \\
\text { characteristic }\end{array}$} & \multicolumn{3}{|c|}{ Gender } & \multicolumn{2}{c|}{ Total } \\
\cline { 2 - 7 } & \multicolumn{2}{|c|}{ Male } & \multicolumn{2}{c|}{ Female } & \multicolumn{2}{c|}{} \\
\hline Age & & & & & & \\
\hline - 5-14 & 16 & 18.39 & 39 & 33.05 & 55 & 26.83 \\
\hline - 15-24 & 27 & 31.03 & 34 & 28.81 & 61 & 29.76 \\
\hline - 25-54 & 16 & 18.39 & 21 & 17.80 & 37 & 18.05 \\
\hline - 55+ & 28 & 32.18 & 24 & 20.34 & 52 & 25.37 \\
\hline Education & & & & & & \\
\hline - No education & 16 & 18.39 & 39 & 33.05 & 55 & 26.83 \\
\hline - Junior High School & 31 & 35.63 & 36 & 30.51 & 67 & 32.68 \\
\hline - Senior High School & 14 & 16.09 & 14 & 11.86 & 28 & 13.66 \\
\hline - Graduate & 18 & 20.69 & 19 & 16.10 & 37 & 18.05 \\
\hline - Postgraduate/master & 2 & 2.30 & 4 & 3.39 & 6 & 2.93 \\
\hline degree & & & & & & \\
\hline - unknown & 6 & 6.90 & 6 & 5.08 & 12 & 5.85 \\
\hline Occupation & & & & & & \\
\hline - Civil servant & 5 & 5.75 & 3 & 2.54 & 8 & 3.90 \\
\hline $\begin{array}{l}\text { - Privat sector } \\
\text { employeee }\end{array}$ & 3 & 3.45 & 3 & 2.54 & 6 & 2.93 \\
\hline - Enterpreneur & 13 & 14.94 & 6 & 5.08 & 19 & 9.27 \\
\hline - Housewife & 0 & 0.00 & 21 & 17.80 & 21 & 10.24 \\
\hline - Retired & 21 & 24.14 & 9 & 7.63 & 30 & 14.63 \\
\hline - Student & 45 & 51.72 & 76 & 64.41 & 121 & 59.02 \\
\hline Monthly income & & & & & & \\
\hline - - IDR 120 000 & 13 & 14.94 & 26 & 22.03 & 39 & 19.02 \\
\hline $\begin{array}{l}\text { - IDR 120 000 } \\
\text { IDR 279 999 }\end{array}$ & 25 & 28.74 & 37 & 31.36 & 62 & 30.24 \\
\hline $\begin{array}{l}\text { - IDR 280 000 } \\
\text { IDR 1 499 999 }\end{array}$ & 13 & 14.94 & 33 & 27.97 & 46 & 22.44 \\
\hline - > IDR 1 499 999 & 36 & 41.38 & 22 & 10.64 & 58 & 28.29 \\
\hline
\end{tabular}

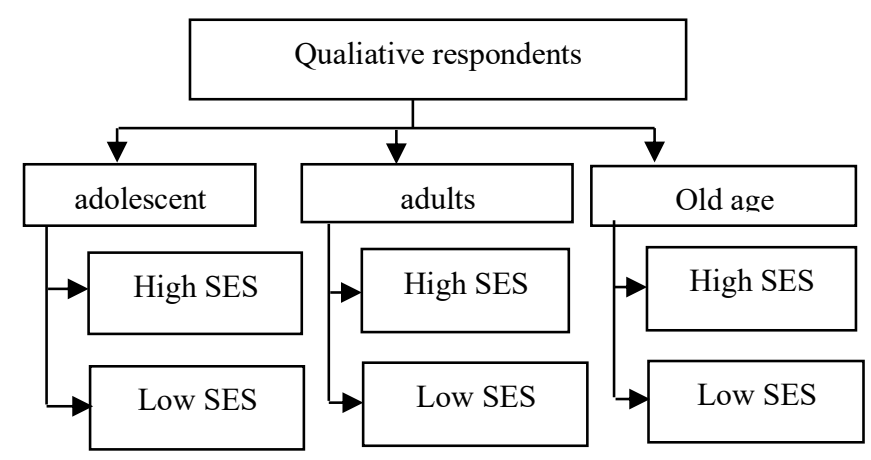

Fig. 1. Qualitative respondents

\subsection{Setting}

The study was conducted in Yogyakarta city from September to December 2016. Quantitative data were collected using survey. Quantitative data collections for cadres were conducted during a cadre meeting at the district health office of Yogyakarta city. Quantitative data collection for elementary and high school students were carried out in 4 public and private elementary and high schools in Yogyakarta city.

\subsection{Data collection}

Quantitative data were collected using a questionnaire adapted from the European Social Survey (ESS) core module in the media and communication section [21]. The questionnaire consisted of 22 open and closed questions that explored the respondents' experience when they saw media campaign about healthy lifestyle and cleanliness that were developed by District Health Office of Yogyakarta city. There were 11 healthy 
lifestyle and cleanliness media evaluated in this study. The media were created by District Health Office of Yogyakarta city in 2005 to 2017. In total, there were 5 billboards, 1 poster, 2 stickers, 1 leaflet and 2 guidebooks evaluated in this study. The picture of each media was presented in Figure 2. All of these media had been distributed in several public places Yogyakarta city. In conducting the evaluation, each media was printed on A4 paper. Participants were then asked to answer questions related to the familiarity, perceptions and responses of the healthy lifestyle and cleanliness media.

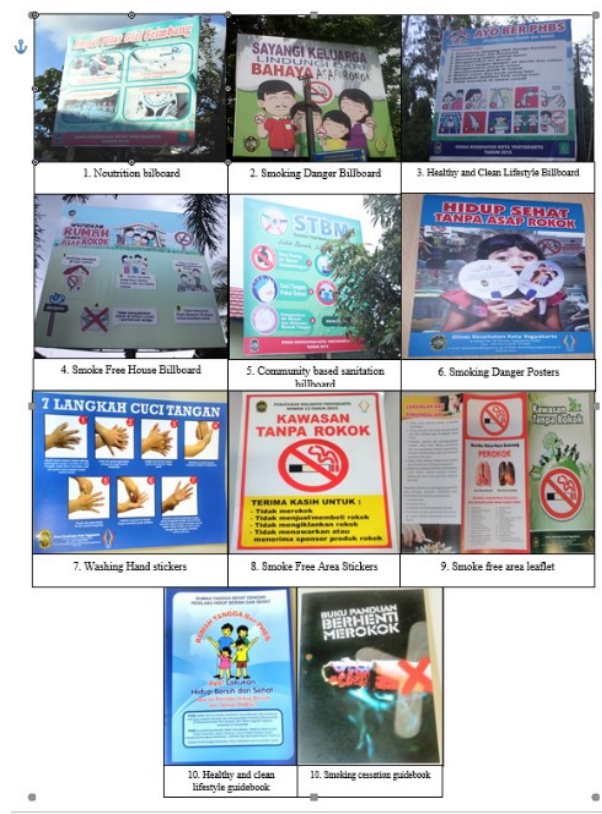

Fig. 2. Healthy behaviour and cleanliness media developed by District Health Office of Yogyakarta city

Qualitative data were collected through eight focus group discussions and one in-depth interview. Each data collection methods were guided by a guideline that consists of seven open ended questions regarding the opinion of the participants regarding health promotion media in Yogyakarta city. Focus group discussions were conducted in four villages with high socioeconomic status and four villages with low socioeconomic status. The selection of the village was conducted by a discussion with district health office. Two research assistants conducted focus group discussions for $60 \mathrm{~min}$ to $90 \mathrm{~min}$ at the village hall or one of participant's houses.

\subsection{Data analysis}

Quantitative and quantitative data were analysed descriptively. Quantitative data were analysed using STATA 13 software. Qualitative data were analysed using OpenCode software.

\subsubsection{Ethical consideration}

Before conducting this study, the researcher sent the protocol to be reviewed by the review board of Faculty of Medicine, Public Health and Nursing, Universitas
Gadjah Mada Indonesia. Ethical clearance was obtained in 2016 and was renewed in 2020 following the analysis of the data with the letter from ethical review board of Faculty of Medicine, Public Health and Nursing, Universitas Gadjah Mada, Indonesia Ref. no: $\mathrm{KE} / \mathrm{FK} / 0712 / \mathrm{EC} / 2020$. Before the data collection, participants were provided with a document that explained the research process, benefit and risk in involving in the research as well as the utilization of the data and the guarantee of data confidentiality. For participants under the age of 17 , the document was sent to the parents with the assistance of school-teacher to be signed by the parents. Data collections were conducted after all the participants and parents agree to involve in the research and signed the document.

\section{Results}

The respondents of this study were 288 people (205 quantitative, 83 qualitative). Participants in quantitative research are spread evenly at 4 levels of age, namely children, adolescents, adults and the elderly. Meanwhile, the majority of respondents' monthly income $(30.24 \%)$ was IDR 120000 to IDR 279000. This is because more than $50 \%$ of respondents in this study were students.

The quantitative data showed that healthy lifestyle and cleanliness media produced by District Health Office of Yogyakarta city could not reach all respondents in this study. Most of the media was not known by more than $50 \%$ of respondents. Respondent's familiarity to the media varies by the type of media. The respondent's familiarity with the guidebook media, for example, was lower than other media. The media with the highest familiarity was sticker with a percentage of more than $60 \%$. The detail of quantitative results were presented in Figure 3.

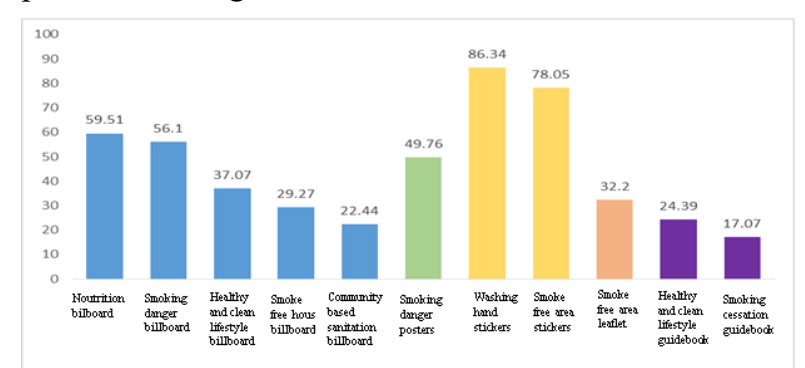

Fig. 3. Participants' familiarity to healthy behaviour and cleanliness media developed by District Health Office of Yogyakarta city

Respondents stated that they had paid attention to the media placed in various health services and public locations. However, booklets were rarely encountered by respondents. According to respondents, booklets were mostly given to cadres and only placed in libraries and not distributed. Qualitative results in this study offered four themes in explaining participants' perception of health promotion media and the cause of participant's unfamiliarity to the healthy behaviour and cleanliness media as follow: 


\subsection{Strategic information and media location}

According to participants, the low level of public familiarity to some health promotion media was caused by the lack of strategic placement of the media. From qualitative research, respondents pay little attention to information through posters, billboards and videotrons because the placement is less strategic and difficult to remember.

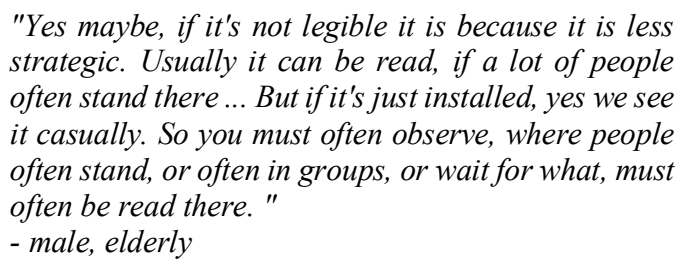

Some participants felt that the health information that placed in public places was mostly related to smoking prevention. While other health issues such as exclusive breastfeeding were rarely found. In addition, participants also hoped that the information in the billboard could be adapted in posters and placed in every neighbourhood in Yogyakarta city.

\subsection{Competition with other information}

Participants stated that they encountered more information regarding traditional treatments compared to information about medical treatments from reliable sources, such as public health centres or doctors. Provision of information about alternative/traditional medicine was obtained from various ways and channels causing participants to be more familiar with those unreliable information.

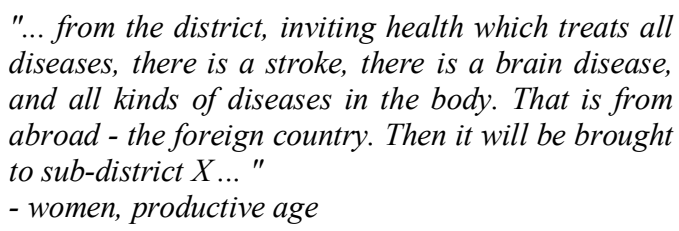

In addition, participants also stated that the vast amount of outdoor media such as billboards or videotrons could make them missed the health message placed in the same location. Participants highlight that healthy lifestyle and cleanliness media were often missed in the provision of another interesting media.

"I think it's also (billboards) are still necessary. Inside, in certain places it is still necessary. Short language. If a lot of writing is even illegible. I think like in the park there is universal health coverage (information) and so on, it's still necessary. Only now our billboards are inferior to advertisements. Little billboards, big ads "

- male, elderly

\subsection{Message distribution}

Participants stated that they did not get much information about health, especially about healthy behaviour and cleanliness, from reliable sources.
Participants expected information to be delivered directly in person so they can ask questions and interact with the message provider. However, information from primary health care workers was not routinely given. Participants stated that to obtain health message, they need to find it by themself.

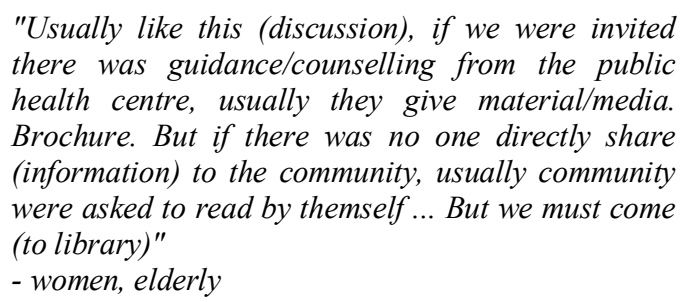

Media expert that became one of our participants was also observed the same thing. Placement of the media in certain locations, such as health care centres, caused limited media coverage only for people visiting health services. This hindered the health provider to achieve their goals by developing the media.

\begin{abstract}
"If it's in, just place it in the health centre, then of course the market, ee, the audience is more limited, it cannot reach all of them ... That is, the market targeted by the health media earlier, in the places of the health center, is ham, half, it means se, some of them already understand, so that fewer and fewer targets are targeted, touched targets. Therefore, as a result the costs that come out, can only be a little" -media expert, male
\end{abstract}

\subsection{Suitability of information channel}

Information on healthy lifestyle and cleanliness was conveyed through various channels, both through audio visual or printed media and direct delivery. One of the District Health Office of Yogyakarta city programs that delivered health information through mosque speakers, for example, was of concern to respondents. Difficulty of application and its impact on social conditions in the community were considered by respondents to hinder the program. As a result, the program could not reach the desired target.

\begin{abstract}
"Health information through mosque loudspeakers has been a long time ago, miss. Previously, we actually got it too. But the term is like, commercialized, no, like a campaign, and residents are disturbed ... That there are those who object. Yes then we stop "

- male, productive age.
\end{abstract}

\section{Discussions}

The study results showed that most respondents have not been exposed to many messages made, for example, through billboards. The billboard location is less strategic, and too much message content is the subject of evaluation by respondents. Billboards are unique outdoor media because the media market is constantly moving, while the location of static media. The message conveyed through billboards needs to be kept short and concise so that one can understand in a short time. 
Placement in accordance with the characteristics of the recipient of the message increases the effectiveness of the message. In addition, a unique display by utilizing the area outside the billboard can attract someone's attention so they are interested in seeing further messages [21, 22].

While the media where the public has been exposed to a lot is a sticker media that only covers a number of issues from PHBS. The thing done by the respondent when receiving a message is still in the condition of being exposed to the message until it starts to be interested in the message. This needs to be considered by the government in making messages, so that messages do not repeat themselves and meet the needs of the community.

Another interesting thing that emerged in this study is the importance of detailed media planning, according to the target and sequential / sequential. Evaluation results show that the government's health media that is most widely known by respondents are stickers. This is because the media is in various places. In this case, media access or proximity to respondents has a greater role. Various innovations can be made to bring the media or health information to the public.

Health information planning requires an ongoing cycle after evaluation. This also applies to health information provided through social media and other internet-based media. Sustainable planning provides an opportunity to increase the effectiveness of providing health information to the community [23. In addition, direct information provision also needs to be carried out so that the community has a comprehensive understanding of a health issue [24].

\section{Conclusion}

The public needs health information that can be accessed easily, quickly, interactively and reliably. Situational analysis and planning are needed in detail by taking into account the characteristics of the target.

All the District Health Office of Yogyakarta city media that were evaluated, the community was more familiar with sticker media than billboards, posters, leaflets and booklets. This is because the media is easy to find and has clear visualizations. The development of media through television and the internet is promising for teens and productive. In the elderly community, health information needs to be brought closer through community meetings and easy access to print media.

This study was funded by District Health Office of Yogyakarta City, Special Region of Yogyakarta, Indonesia in 2017

\section{References}

1. WHO, Health Promotion. Health Topics. 2017.

2. K. Glanz, B.K. Rimer, K. Viswanath. Health Behavior and Health Education: Theory, Research, and Practice [Internet]. Education. 23-38. (2008). Available from: $\underline{\mathrm{http}}$ //books.google.com/books?id=WsHxyj710Ug $\underline{\mathrm{C}}$
3. N.J. Ammary-Risch, A. Zambon, K.M. Brown, Communicating health information effectively. In: C.I. Fertman, D.D. Allensworth, (Eds) Health Promotion Programs: From theory to practice. San Francisco, CA: Jossey-Bass, (2010). p. 203-258.

4. L. Jack Jr., M. Grim, T. Gross, S. Lynch, C. McLin, Theory in health promotion program. In: C.I. Fertman, D.D. Allensworth, editors. Health Promotion Programs: From theory to practice. San Francisco, CA: Jossey-Bass; (2010), p. 57-90.

5. D. Wu, T. Yang, R.R. Cottrell, H. Zhou, X.Y. Yang, Y. Zhang, Health Educ. J., 74, 3, 287-298 (2015).

6. F-C. Chang, H-Y. Sung, S-H. Zhu, T-Y. Feng, S-T. Chiou. Am J Health Promot., 43-51 (2015).

7. B.J. O’Hara, P. Phongsavan, K. Gebel, D. Banovic, K.M. Buffett, A.E. Bauman. Health Promot Pract., 15, 6, 828-838 (2014).

8. A. Bień, K. Rzońca, M. Zarajczyk, G.J. IwanowiczPalus, A. Kozak, Polish Journal of Public Health, 126, 3, 103-106 (2016).

9. Kementerian Kesehatan Republik Indonesia. Riset Kesehatan Dasar 2013. Riset Kesahatan Dasar. (2013). [in Bahasa Indonesia].

10. Dinas Kesehatan DIY. Profil Kesehatan DIY 2015. Daerah Istimewa Yogyakarta, (2015). [in Bahasa Indonesia].

11. Kelompok Kerja Sanitasi Kota Yogyakarta. Buku Putih Sanitasi Kota Yogyakarta. Yogyakarta, (2012). [in Bahasa Indonesia].

12. R.E. Glasgow, L.M. Klesges, D.A. Dzewaltowski, P.A. Estabrooks, T.M. Vogt. Health Educ Res., 21, 5, 688-694 (2006).

13. Centers for Disease Control and Prevention. Framework for program evaluation in public health. MMWR Recomm Rep [Internet]. 48(RR11), 1-40 (1999). Available from: http://www.pubmedcentral.nih.gov/articlerender.fc gi? artid $=2578767 \&$ tool $=$ pmcentrez\&rendertype $=\mathrm{a}$ bstract

14. B.L. Neiger, R. Thackeray, S.A. Van Wagenen, C.L. Hanson, J.H. West, M.D. Barnes, M.C. Fagen, Health promotion practice, 13, 2, 159-164 (2012).

15. C.W. Metzler, M.R. Sanders, J.C. Rusby, R.N. Crowley, Behav Ther., 43, 2, 257-270 (2012).

16. R.E. Glasgow, E. Lichtenstein, A.C. Marcus. Am J Public Health., 93, 8, 1261-1267 (2003).

17. H.F. Huye, C.L. Connell, L.B. Crook, K. Yadrick, J. Zoellner, J Nutr Educ Behav., 46(1):34-42 (2014).

18. R. Glasgow, T. Vogt, S. Boles, Am J Public Health, 89, 9, 1322-1327 (1999).

19. J.R. Finnegan, K. Viswanath, Communication theory and health behavior change: The media studies framework. In: K. Glanz, B.K. Rimer, K. Viswanath, Health Behavior and Health Education: Theory, Research, and Practice. Fifth Edit. San Francisco, CA: John Wiley \& Sons, Ltd.; (2008), p. 363-88. 
20. Eropean Social Survey. Source Questionnaire European Social Survey (ESS) [Internet]. 2016 [cited 2017 Feb 5]. Available from: http://www.europeansocialsurvey.org/methodolog y/ess_methodology/source questionnaire

21. E.B. Franch, C.B. Albiol, Online Journal of Communication and Media Technologies, 3, 2, 94111 (2013).

22. K.A. Calderwood, W.J. Wellington, Health promotion practice, 16, 4, 510-522 (2015). Available at: http://www.ncbi.nlm.nih.gov/pubmed/25586130.

23. J. Sligo, et al., International Journal of Medical Informatics, 97, 86-97 (2017). Available at: http://linkinghub.elsevier.com/retrieve/pii/S13865 05616302003.

24. S.S. Nouri, R.E. Rudd, Patient education and counseling, 98, 5, 565-571 (2015). Available at: http://www.sciencedirect.com/science/article/pii/S $\underline{0738399114005242}$ 